\title{
Readmission after lung cancer resection is associated with a 6-fold increase in 90-day postoperative mortality
}

\author{
Yinin $\mathrm{Hu}, \mathrm{MD},{ }^{\mathrm{a}}$ Timothy L. McMurry, PhD, ${ }^{\mathrm{b}}$ James M. Isbell, MD, MSCI, ${ }^{\mathrm{a}}$ \\ George J. Stukenborg, $\mathrm{PhD},{ }^{\mathrm{b}}$ and Benjamin D. Kozower, MD, $\mathrm{MPH}^{\mathrm{a}, \mathrm{b}}$
}

Objectives: Postoperative readmission affects patient care and healthcare costs. There is a paucity of nationwide data describing the clinical significance of readmission after thoracic operations. The purpose of this study was to evaluate the relationship between postoperative readmission and mortality after lung cancer resection.

\begin{abstract}
Methods: Data were extracted for patients undergoing lung cancer resection from the linked Surveillance Epidemiology and End Results-Medicare registry (2006-2011), including demographics, comorbidities, socioeconomic factors, readmission within 30 days from discharge, and 90-day mortality. Readmitting facility and diagnoses were identified. A hierarchical regression model clustered at the hospital level identified predictors of readmission.
\end{abstract}

Results: We identified 11,432 patients undergoing lung cancer resection discharged alive from 677 hospitals. The median age was 74.5 years, and $52 \%$ of patients received an open lobectomy. Thirty-day readmission rate was $12.8 \%$, and $28.3 \%$ of readmissions were to facilities that did not perform the original operation. Readmission was associated with a 6 -fold increase in 90 -day mortality $(14.4 \% \mathrm{vs} 2.5 \%, P<.001)$. The most common readmitting diagnoses were respiratory insufficiency, pneumonia, pneumothorax, and cardiac complications. Patient factors associated with readmission included resection type; age; prior induction chemoradiation; preoperative comorbidities, including congestive heart failure and chronic obstructive pulmonary disease; and low regional population density.

Conclusions: Factors associated with early readmission after lung cancer resection include patient comorbidities, type of operation, and socioeconomic factors. Metrics that only report readmissions to the operative provider miss one-fourth of all cases. Readmitted patients have an increased risk of death and demand maximum attention and optimal care. (J Thorac Cardiovasc Surg 2014;148:2261-7)

See related commentary on pages $2267-8$.

Supplemental material is available online.

Lung cancer is the leading cause of cancer death in the United States, ${ }^{1}$ and resection remains the treatment of choice for appropriate surgical candidates with early-stage disease. ${ }^{2}$ Early postoperative readmission is not only clinically relevant ${ }^{3}$ but also an important predictor of increased resource use. ${ }^{4}$ Beginning in October of 2012, the Affordable Care Act established the Hospital Readmissions

\footnotetext{
From the Division of Thoracic Surgery, ${ }^{\mathrm{a}}$ Department of Surgery and Department of Public Health Sciences, ${ }^{\mathrm{b}}$ University of Virginia Health System, Charlottesville, Va. Funded by the Agency for Healthcare Research and Quality: K080HS18049. Disclosures: Authors have nothing to disclose with regard to commercial support. Received for publication Jan 29, 2014; revisions received March 25, 2014; accepted for publication April 11, 2014; available ahead of print May 10, 2014.

Address for reprints: Benjamin D. Kozower, MD, MPH, University of Virginia Health System, General Thoracic Surgery, PO Box 800679, Charlottesville, VA 229080679 (E-mail: bdk8g@virginia.edu).

$0022-5223 / \$ 36.00$

Copyright (c) 2014 by The American Association for Thoracic Surgery http://dx.doi.org/10.1016/j.jtcvs.2014.04.026
}

Reduction Program, reducing Medicare payments for excess readmissions for acute myocardial infarction, pneumonia, and heart failure. ${ }^{5}$ Because most early postoperative readmissions are perceived as preventable, incentives to reduce their occurrence are likely forthcoming in the future.

Currently, there is a paucity of national data describing the frequency of postoperative readmissions after lung cancer resection. Data from the American College of Surgeons National Surgical Quality Improvement Program report 30day readmission after all thoracic operations to be $11.9 \%$, but further granularity is necessary to elaborate a pragmatic quality metric. Although the development of a risk-adjusted readmission metric for coronary artery bypass surgery is under way through the Society of Thoracic Surgeons (STS), such a process is nonexistent for pulmonary resections. The STS General Thoracic Surgery Database includes postoperative outcomes up to 30 days for member providers, but because the STS is composed primarily of thoracic surgery specialists, ${ }^{8}$ the Surveillance Epidemiology and End Results (SEER)-Medicare database may better represent operative experiences nationwide. ${ }^{9}$

The primary objectives of this study were to determine the frequency and associated risk factors of early readmission after lung cancer resection and to assess the impact 


\section{Abbreviations and Acronyms \\ $\mathrm{OR}=$ odds ratio \\ SEER $=$ Surveillance Epidemiology and End Results \\ STS $=$ Society of Thoracic Surgeons \\ VATS $=$ video-assisted thoracoscopic surgery}

of readmission on 90-day outcomes. We hypothesized that readmission within 30 days of discharge is associated with an increased risk of subsequent mortality.

\section{METHODS \\ Surveillance Epidemiology and End Results-Medicare Database}

The SEER registry is a population-based collection of incident cases and includes cancer diagnostic, descriptive, and therapeutic information relevant to the time of diagnosis. The National Cancer Institute links the SEER registry to Medicare data for eligible patients to provide comprehensive information on survival, inpatient admissions, outpatient events, and other healthcare claims for $93 \%$ of patients aged 65 years or more. ${ }^{10}$ These data accurately account for postoperative readmissions and are not limited to readmissions taking place at the facilities providing the index operation. The combined SEER-Medicare database encompasses approximately $26 \%$ of the population and provides an opportunity for longitudinal studies broadly generalizable to the Medicare population.

\section{Patient Selection}

The 2006 to 2010 SEER-Medicare database was used to identify records for all patients aged 66 years or more with non-small cell lung cancer of any stage by American Joint Committee on Cancer criteria who received surgical resection. ${ }^{11}$ Exclusionary criteria included enrollment in a Medicare Health Maintenance Organization, lung cancer diagnoses made at autopsy, prior lung cancer diagnoses within 1 year of index diagnosis, missing date of diagnosis, wedge resection for stage IV disease, and death before discharge from the operative admission. To ensure that all patients had adequate presurgical records to identify comorbid diseases present at the time of surgery, we also excluded patients who were not eligible for Medicare during the 3 months before surgery or who were diagnosed in 2006.

Demographic information available in the SEER-Medicare data included age, gender, race, and the operative and readmitting facilities. Clinical data included year of operation, final pathologic stage, procedure type and approach, preoperative comorbidities, and readmission diagnoses. To differentiate between readmissions for operative complications and unrelated readmissions, a panel of International Classification of Diseases, Ninth Revision codes composed of respiratory, infectious, cardiac, wound, and renal diagnoses were matched to readmission diagnoses recorded in the SEER-Medicare database (Table E1). Comorbidities were identified using the Deyo modification of the Charlson index ${ }^{12}$ and were defined using criteria provided by the National Cancer Institute for use with diagnoses reported within inpatient files (Medicare Provider Analysis and Review), outpatient files (Outpatient Statistical Analysis File), and physician claims data (National Claims History). ${ }^{13,14}$ Mortality measures were based on Medicare death certificate records within the SEER-Medicare database. The primary outcomes were readmission within 30 days of discharge from the operative admission and mortality within 90 days of surgery.

\section{Statistical Analyses}

The mortality rate within 90 days of surgery was compared between the readmitted and nonreadmitted patient groups. Subgroup analyses included mortality rate comparisons based on the readmitting facility (operative vs nonoperative) and readmitting diagnosis (operative complication vs unrelated). To compare mortality rates between patients who were readmitted and patients who were not, a hierarchical generalized linear model for 90-day mortality using previously reported model predictors in addition to 30-day readmission and restricted to patients who were discharged alive was created. ${ }^{15}$ A single hierarchical generalized linear model was used to estimate risk of readmission, with adjustments for data clustered by treatment provider. Model predictors were selected a priori on the basis of literature review and frequency of occurrence within our dataset, and included both clinical and socioeconomic risk factors. The statistical significance of each predictor of readmission included in the models was assessed using the $\mathrm{F}$ test statistic. A test for provider covariance was performed to determine whether risk-adjusted readmission rates varied significantly between operative providers. All outcomes data were analyzed using SAS version 9.3 (SAS Institute, Inc, Cary, NC) and R version 3.0.2 statistical software. ${ }^{16}$ The University of Virginia Institutional Review Board for Health Sciences Research approved this study.

\section{RESULTS}

For patients diagnosed with non-small cell lung cancer between 2007 and 2009, SEER-Medicare captured 11,432 patients who were discharged alive after resection and who met all inclusion criteria. The median age was 74.5 years at the time of surgery, and most patients presented with stage I disease $(70.4 \%)$. Approximately half of patients were female $(51.5 \%)$, and the predominant race was white $(89.7 \%)$. The most common procedure performed was an open lobectomy $(51.6 \%)$, and thoracoscopic approaches accounted for $26.8 \%$ of resections (Table 1 ). The most common preoperative comorbidities were chronic pulmonary disease, diabetes, and peripheral vascular disease. Patients included within the final study population were treated at 677 hospitals.

The overall readmission rate within 30 days of discharge was $12.8 \%(1461 / 11,432)$, and $28.3 \%(414 / 1461)$ of readmissions were to facilities that did not perform the index operation. The median length of stay during postoperative readmissions was 4 days (interquartile range, 2-7 days). Readmissions were more frequent within the first 2 weeks after discharge (Figure 1). The mortality rate within 90 days of surgery was approximately 6 times higher among patients who experienced at least 1 early readmission (odds ratio [OR], 6.6; $14.4 \%$ [210/1461] vs $2.5 \%$ [249/9971], $P<.001)$. Among readmitted patients, those who underwent 2 or more readmissions within 60 days of discharge did not have a significantly higher 90 -day mortality rate than those readmitted only once $(16.2 \%, 58 / 358$ vs $13.8 \%, 152 / 1103, P=.295)$. In a hierarchical generalized linear model for 90-day mortality, postoperative readmission within 30 days had the largest contribution to predicting mortality risk (OR, 5.79; $P<.001$, F-test statistic 291). The model C-statistic was 0.80 (Table 2).

Ninety-day mortality did not differ between patients who were readmitted to the operative facility and patients who were readmitted to an alternate facility $(13.6 \%$ vs $16.4 \%$, $P=.16)$. However, of patients initially readmitted to a 
TABLE 1. Patient demographics and preoperative comorbidities

\begin{tabular}{|c|c|}
\hline Demographics & n $(\%)$ \\
\hline \multicolumn{2}{|l|}{ Age, $y$} \\
\hline $65-69$ & $2653(23.2)$ \\
\hline $70-74$ & $3437(30.1)$ \\
\hline $75-79$ & $3045(26.6)$ \\
\hline $80-84$ & $1751(15.3)$ \\
\hline $85+$ & $546(4.8)$ \\
\hline \multicolumn{2}{|l|}{ Gender } \\
\hline Male & $5545(48.5)$ \\
\hline Female & $5887(51.5)$ \\
\hline \multicolumn{2}{|l|}{ Year of diagnosis } \\
\hline 2007 & $3871(33.9)$ \\
\hline 2008 & $3823(33.4)$ \\
\hline 2009 & $3738(32.7)$ \\
\hline \multicolumn{2}{|l|}{ Race } \\
\hline White & $10,252(89.7)$ \\
\hline Black & $607(5.3)$ \\
\hline Asian & $257(2.3)$ \\
\hline Hispanic & $79(0.7)$ \\
\hline Other & $229(2.0)$ \\
\hline \multicolumn{2}{|l|}{ Tumor stage } \\
\hline I & $7906(70.4)$ \\
\hline II & $1270(11.3)$ \\
\hline III & $1682(15.0)$ \\
\hline IV & $366(3.3)$ \\
\hline Not available & $201(1.8)$ \\
\hline \multicolumn{2}{|l|}{ Operation } \\
\hline Open lobectomy/bilobectomy & $5904(51.6)$ \\
\hline Open wedge resection & $1244(10.9)$ \\
\hline Open segmentectomy & $803(7.0)$ \\
\hline Open pneumonectomy & $334(2.9)$ \\
\hline Chest wall resection with lung & $88(0.8)$ \\
\hline VATS lobectomy & $1625(14.2)$ \\
\hline VATS wedge resection & $940(8.2)$ \\
\hline VATS segmentectomy & $494(4.3)$ \\
\hline \multicolumn{2}{|l|}{ Comorbidities } \\
\hline Induction chemoradiation & $563(4.9)$ \\
\hline Myocardial infarction & $1172(10.3)$ \\
\hline Heart failure & $1262(11.0)$ \\
\hline Peripheral vascular disease & $1743(15.2)$ \\
\hline Cerebral vascular disease & $1129(9.9)$ \\
\hline Chronic pulmonary disease & 7078 (61.9) \\
\hline Diabetes & $3476(30.4)$ \\
\hline Chronic renal failure & $1012(8.9)$ \\
\hline
\end{tabular}

VATS, Video-assisted thoracoscopic surgery.

nonoperative facility, $11.8 \%(49 / 414)$ were transferred before discharge, compared with $0.86 \%$ of patients readmitted to the operative facility $(9 / 1047, P<.001)$. Readmitted patients who were subsequently transferred had a higher 90 -day mortality rate than those who were not $(25.9 \%, 15 /$ 58 vs $13.9 \%, 195 / 1403, P=.011)$, suggesting that transfers of care were likely related to clinical acuity. On the basis of primary admitting diagnoses, 54.1\% (791/1461) of readmissions were directly related to postoperative complications, the most common of which were respiratory

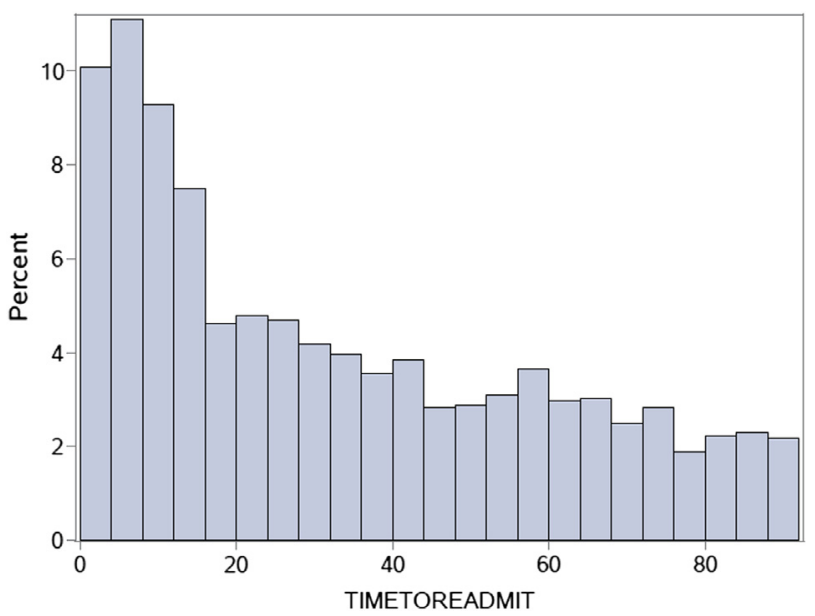

FIGURE 1. Time to readmission after discharge from lung cancer resection. Although early readmissions occur most frequently during the first 2 weeks after discharge, occurrences persist beyond 3 months.

insufficiency $(24.0 \%, 190 / 791)$, pneumonia $(16.7 \%, 132 /$ $791)$, cardiac complications $(14.8 \%, 117 / 791)$, and pneumothorax $(13.7 \%, 108 / 791)$ (Figure 2). Mortality at 90 days did not differ significantly between patients readmitted because of operative complications and patients readmitted with unrelated primary diagnoses $(\mathrm{OR}, 1.22 ; P=.21)$.

Hierarchical generalized regression models were used to estimate the risk of readmission within 30 days of discharge. Hospital provider was included in the models as a random effect, accounting for the clustering of procedures within hospitals. The $\mathrm{C}$-statistic for the predictive accuracy of the model was 0.604. Predictors of early readmission with the highest F-statistic in descending order were chronic obstructive pulmonary disease, congestive heart failure, prior induction chemoradiation, recent myocardial infarction, and chronic renal failure (Table 3). Of the procedure types evaluated, pneumonectomy and combined lung and chest wall resection had the highest ORs of early readmission. Of note, when compared with video-assisted thoracoscopic surgery (VATS) wedge resections, more extensive VATS resections were associated with a lower 30-day readmission rate. Among socioeconomic factors, regional population density was associated with readmission, whereas regional high school nongraduation rate trended toward an association. The test for provider covariance was not significant $\left(\sigma^{2}=0.05, P=.41\right)$, suggesting that, after adjusting for clinical and socioeconomic risk factors, there was no evidence of significant differences in readmission rates across hospitals.

\section{DISCUSSION}

The present study is the first to report the relationship between early readmission and postoperative mortality within a national lung cancer resection database. Our results 
TABLE 2. Hierarchical regression for risk factors associated with 90-day mortality (model C-statistic: 0.80)

\begin{tabular}{|c|c|c|c|c|}
\hline Variable & OR & CI & $P$ value & F test \\
\hline 30-d readmission & 5.79 & 4.73-7.09 & $<.001$ & 290.7 \\
\hline Procedure type & & & $<.001$ & 13.3 \\
\hline Pneumonectomy & 3.97 & $2.41-6.56$ & & \\
\hline $\begin{array}{l}\text { Chest wall resection } \\
\text { with lung }\end{array}$ & 6.18 & $3.08-12.4$ & & \\
\hline Lobectomy/bilobectomy & 1.06 & $0.72-1.55$ & & \\
\hline Segmentectomy & 1.50 & $0.92-2.43$ & & \\
\hline Wedge resection & 158 & $1.02-2.47$ & & \\
\hline VATS lobectomy & 0.74 & $0.46-1.18$ & & \\
\hline VATS segmentectomy & 0.62 & $0.31-1.26$ & & \\
\hline VATS wedge resection & Reference value & & & \\
\hline Surgical year & & & .028 & 3.0 \\
\hline 2007 & 0.60 & $0.36-0.99$ & & \\
\hline 2008 & 0.75 & $0.46-1.23$ & & \\
\hline 2009 & 0.87 & $0.53-1.40$ & & \\
\hline 2010 & Reference value & & & \\
\hline Age, y & & & .001 & 4.7 \\
\hline $85+$ & 2.28 & $1.49-3.49$ & & \\
\hline $80-84$ & 1.67 & $1.20-2.32$ & & \\
\hline $75-79$ & 1.29 & $0.96-1.74$ & & \\
\hline $70-74$ & 1.22 & $0.91-1.64$ & & \\
\hline $65-69$ & Reference value & & & \\
\hline Gender & & & $<.001$ & 29.6 \\
\hline Female & 0.56 & $0.46-0.69$ & & \\
\hline Male & Reference value & & & \\
\hline Race & & & .263 & 1.3 \\
\hline Asian & 0.39 & $0.14-1.07$ & & \\
\hline Black & 0.94 & $0.60-1.49$ & & \\
\hline Other & 0.75 & $0.39-1.47$ & & \\
\hline White & Reference value & & & \\
\hline \multicolumn{5}{|l|}{ Comorbidity } \\
\hline Induction chemoradiation & 1.44 & $0.99-2.10$ & .055 & 3.7 \\
\hline Acute MI & 0.85 & $0.62-1.17$ & .329 & 1.0 \\
\hline $\mathrm{CHF}$ & 1.95 & $1.52-2.51$ & $<.001$ & 27.1 \\
\hline PVD & 1.07 & $0.83-1.39$ & .604 & 0.3 \\
\hline Cerebrovascular disease & 1.10 & $0.82-1.49$ & .532 & 0.4 \\
\hline COPD & 1.27 & $1.02-1.58$ & .035 & 4.4 \\
\hline Diabetes & 1.07 & $0.86-1.34$ & .532 & 0.4 \\
\hline Renal failure & 1.15 & $0.86-1.56$ & .347 & 0.9 \\
\hline
\end{tabular}

$C H F$, Congestive heart failure; $C I$, confidence interval; $C O P D$, chronic obstructive pulmonary disease; $M I$, myocardial infarction; $O R$, odds ratio; $P V D$, peripheral vascular disease; VATS, video-assisted thoracoscopic surgery.

suggest that readmission within 30 days of discharge is common and substantially underestimated by metrics that only report readmissions to the operative facility. Even more important, early readmission after lung cancer resection is associated with a 6-fold increase in the risk of death. Our results highlight the acuity of patients readmitted after lung resections and argue for intensified resource allocation and clinical awareness. When presented with these patients, clinicians should maintain a low threshold for admission to intensive care units and transfer to tertiary care centers.
Our study using SEER-Medicare data encompasses a large, diverse group of hospitals. Within this group, overall 30-day readmission rate after lung cancer resection was $12.8 \%$. This finding is in concordance with outcomes derived from 1992-2002 SEER-Medicare data showing a $15 \% 30$-day readmission rate, ${ }^{4}$ suggesting that risk of postoperative readmission in this population has not changed significantly over the last 15 years. Freeman and colleagues ${ }^{17}$ recently reported a $7 \%$ operation-related, 90-day readmission rate and an $8.3 \%$ overall readmission rate within a high-volume, multi-institutional database. Likewise, Varela and colleagues ${ }^{18}$ reported an emergency 30 -day readmission rate of $6.9 \%$. Within our dataset, a higher overall readmission rate may be related in part to the older median age of the Medicare population; this is reflected by the high rate of readmissions that were unrelated to the index operation $(45.9 \%)$ ). Isolating readmissions related to postoperative complications revealed an occurrence rate of $6.9 \%$, which is in concordance with prior studies. A higher rate of readmissions unrelated to the index operation within our dataset also may be due to inclusion of more low-volume centers in areas with less abundant outpatient resources. However, testing for provider covariance within our dataset showed that risk-adjusted readmission rates did not differ significantly between hospitals. This finding likely reflects the wide range of provider case volumes, which greatly reduces the utility of readmission rate as a differentiating quality metric.

Our analyses demonstrate that 30-day readmission after lung cancer resection is the strongest risk factor for 90day mortality, outperforming all commonly reported preoperative predictors. Furthermore, this association was independent of the readmitting facility (operative vs nonoperative) and the readmission category (operative complication vs unrelated). Readmitted patients who were transferred to another facility had a higher 90-day mortality rate than those who were not. Rather than suggesting a causative effect, we believe this association is reflective of the appropriate transfer of high-acuity patients to tertiary care facilities. Single- and multi-institutional data have shown a significant decrease in long-term survival among patients who underwent lung resection and had early readmission. ${ }^{4,19}$ Our results indicate that this effect is even more critical over the initial months after surgery. Although mortality 2 to 5 years after resection may not be regarded as surgically related or preventable, death within 90 days from surgery is more likely to be attributable to the perioperative experience and may offer opportunities for early intervention.

Hierarchical regression demonstrated that socioeconomic factors, such as regional high school nongraduation rate and population density, may be related to the likelihood of postoperative readmission. A recent study within the cardiac surgery community also identified lower education 

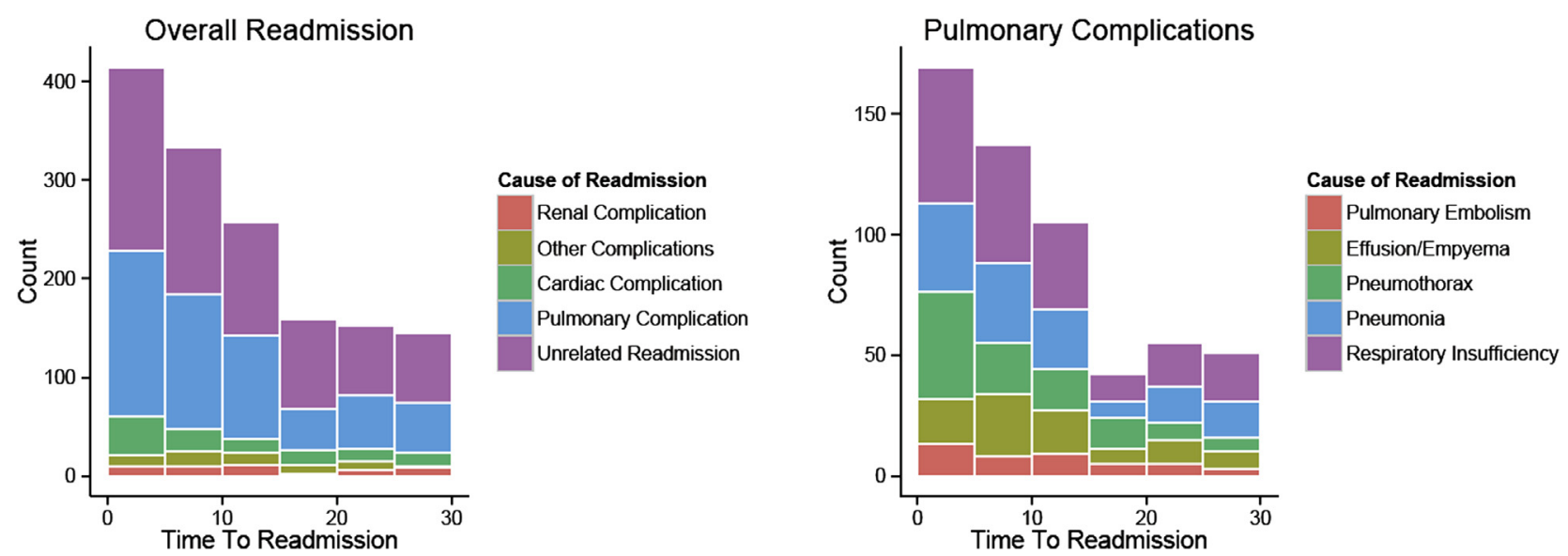

FIGURE 2. Distribution of primary readmitting diagnoses over time. Operative complications comprised 54.1\% (791/1461) of all readmissions (left). Among pulmonary operative complications, the most common readmitting diagnoses were respiratory insufficiency, pneumonia, and pneumothorax (right).

level as a significant risk factor for postoperative readmission. ${ }^{20}$ Although similar results in general thoracic surgery have borne out in a multi-institutional European study relating regional deprivation scores to readmission, ${ }^{21}$ a link between socioeconomic factors and readmission after lung resection has not been demonstrated in the United States. Because of protocols protecting patient confidentiality, a direct analysis of participant census data is not available through SEER-Medicare; thus, socioeconomic surrogate covariates were chosen. The association between regional socioeconomic factors and risk of readmission highlights some of the difficulties with patient education and outpatient care access, and advocates for further development of healthcare infrastructure in disadvantaged regions.

Among preexisting clinical risk factors, chronic obstructive pulmonary disease, congestive heart failure, induction chemoradiation, recent myocardial infarction, renal failure, and age were all significantly associated with rate of readmission. Not surprisingly, pneumonectomy was the operation associated with the highest risk of postoperative readmission. These results are in concordance with most published series $^{4,17,19,21}$ and expand on existing evidence through using a large national database and implementing a hierarchical multiple regression model that adjusts for the provider. Awareness of the most important comorbid risk factors may assist with postoperative management and discharge planning. Among patients who are at high risk for readmission, early postdischarge telephone calls to assess pain control, home oxygen requirements, and adequate performance of activities of daily living may be a simple and inexpensive means to reduce the likelihood of unnecessary readmission. ${ }^{22}$ Such a protocol may allow early identification of warning signs to promote proactive intervention when indicated. Our finding that more extensive VATS resections are associated with a reduced readmission rate compared with VATS wedge resections may be reflective of the fact that more extensive resections tend to be performed in patients with better preoperative functional reserve. ${ }^{23}$ Of note, VATS resections constituted only $26.7 \%$ of the lung resections within our dataset. Minimally invasive procedures may comprise a higher proportion of the operative volume within specialized thoracic centers, such as those represented by the STS General Thoracic Surgery Database. ${ }^{24}$ The frequency and predictors of postoperative readmissions in this setting deserve further focused study.

\section{Study Limitations}

First, the SEER-Medicare database excludes patients aged less than 65 years. Thus, the median age of our dataset is older than the general population undergoing lung cancer resection and may lend selection bias to both the rate of readmission and the rate of 90-day mortality. However, the median age of patients included in this study is only slightly more than the median age at diagnosis for non-small cell lung cancer nationally (70 years). ${ }^{25}$ Furthermore, the average age of patients undergoing lung cancer resection included in the STS database is 67 years, which falls within the Medicare population. ${ }^{24}$ Second, despite accounting for 17 variables, our hierarchical model for early readmission achieved a C-statistic of only 0.604 , indicating that the model had only modest ability to predict future readmissions. Because of the presence of many interrelated and often immeasurable factors that contribute to postoperative readmissions, this outcome has historically been difficult to predict. ${ }^{26}$ For example, an existing 18 -variable readmission model used in a large, single-institution study of patients undergoing cardiac surgery had a C-statistic of only $0.7{ }^{27}$ Likewise, subspecialty-specific American College of Surgeons National Surgical Quality Improvement Program prediction models for readmission also perform modestly, 
TABLE 3. Clinical risk factors for 30 day readmission (model C-statistic: 0.604)

\begin{tabular}{|c|c|c|c|c|}
\hline Variable & OR & CI & $P$ value & F test \\
\hline Procedure type & & & .018 & 2.4 \\
\hline Pneumonectomy & 1.21 & $0.85-1.72$ & & \\
\hline $\begin{array}{l}\text { Chest wall resection with } \\
\text { lung }\end{array}$ & 1.15 & $0.62-2.13$ & & \\
\hline Lobectomy/bilobectomy & 0.82 & $0.66-1.01$ & & \\
\hline Segmentectomy & 0.96 & $0.72-1.27$ & & \\
\hline Wedge resection & 0.78 & $0.60-1.01$ & & \\
\hline VATS lobectomy & 0.74 & $0.58-0.95$ & & \\
\hline VATS segmentectomy & 0.69 & $0.49-0.98$ & & \\
\hline VATS wedge resection & Reference value & & & \\
\hline Surgical year & & & .584 & 0.7 \\
\hline 2007 & 1.08 & $0.78-1.49$ & & \\
\hline 2008 & 1.17 & $0.85-1.61$ & & \\
\hline 2009 & 1.14 & $0.83-1.57$ & & \\
\hline 2010 & Reference value & & & \\
\hline Age, y & & & .025 & 2.8 \\
\hline $85+$ & 1.47 & $1.11-1.94$ & & \\
\hline $80-84$ & 1.22 & $1.00-1.48$ & & \\
\hline $75-79$ & 1.21 & $1.03-1.44$ & & \\
\hline $70-74$ & 1.07 & $0.91-1.26$ & & \\
\hline $65-69$ & Reference value & & & \\
\hline Gender & & & .049 & 3.9 \\
\hline Female & 0.88 & $0.78-1.00$ & & \\
\hline Male & Reference value & & & \\
\hline Race & & & 190 & 1.6 \\
\hline Asian & 0.80 & $0.52-1.24$ & & \\
\hline Black & 0.75 & $0.57-1.01$ & & \\
\hline Other & 0.88 & $0.60-1.28$ & & \\
\hline White & Reference value & & & \\
\hline Comorbidity & & & & \\
\hline Induction chemoradiation & 1.52 & $1.19-1.93$ & $<.001$ & 11.5 \\
\hline $\begin{array}{l}\text { Acute myocardial } \\
\text { infarction }\end{array}$ & 1.25 & $1.01-1.50$ & .015 & 5.9 \\
\hline Congestive heart failure & 1.56 & $1.32-1.83$ & $<.001$ & 27.9 \\
\hline $\begin{array}{l}\text { Peripheral vascular } \\
\text { disease }\end{array}$ & 1.14 & $0.98-1.34$ & .093 & 2.8 \\
\hline Cerebrovascular disease & 1.18 & $0.99-1.42$ & .070 & 3.3 \\
\hline COPD & 1.47 & $1.29-1.67$ & $<.001$ & 34.3 \\
\hline Diabetes & 1.15 & $1.01-1.31$ & .035 & 4.5 \\
\hline Renal failure & 1.25 & $1.04-1.51$ & .018 & 5.6 \\
\hline Married & 0.96 & $0.85-1.09$ & .530 & 0.4 \\
\hline Regional median income & & & .570 & 0.7 \\
\hline Q1 (lowest income) & 0.89 & $0.67-1.18$ & & \\
\hline Q2 & 0.95 & $0.74-1.22$ & & \\
\hline Q3 & 1.06 & $0.85-1.32$ & & \\
\hline Q4 & 1.05 & $0.86-1.29$ & & \\
\hline Q5 (highest income) & Reference value & & & \\
\hline Regional population density & & & .032 & 2.7 \\
\hline Q1 (least dense) & 0.92 & $0.75-1.13$ & & \\
\hline Q2 & 1.15 & $0.95-1.39$ & & \\
\hline Q3 & 1.14 & $0.94-1.38$ & & \\
\hline Q4 & 1.24 & $1.03-1.50$ & & \\
\hline \multirow[t]{2}{*}{ Q5 (most dense) } & Reference value & & & \\
\hline & & & .067 & 2.2 \\
\hline
\end{tabular}

TABLE 3. Continued

\begin{tabular}{lccc}
\hline \multicolumn{1}{c}{ Variable } & OR & CI & $\boldsymbol{P}$ value $\mathbf{F}$ test \\
\hline $\begin{array}{l}\text { Regional high school } \\
\quad \text { nongraduation }\end{array}$ & & \\
Q1 (fewest nongraduates) & 0.79 & $0.60-1.03$ \\
Q2 & 0.73 & $0.57-0.93$ \\
Q3 & 0.91 & $0.73-1.13$ \\
Q4 & 0.97 & $0.79-1.18$ \\
Q5 (most nongraduates) & Reference value &
\end{tabular}

Q5 (most nongraduates) Reference value

$C I$, Confidence interval; $C O P D$, chronic obstructive pulmonary disease; $O R$, odds ratio; $Q$, quintile; VATS, video-assisted thoracic surgery.

with C-statistics between 0.65 and 0.71 , despite incorporating a number of relevant perioperative clinical data. ${ }^{6}$ Because the SEER-Medicare database does not enable separation between preoperative and postoperative diagnosis codes within index operative admissions, we were unable to reliably account for postoperative complications within our predictive models. The moderate C-statistic notwithstanding, the present hierarchical multivariate regression model augments existing univariate analyses within the thoracic literature and highlights preoperative factors that warrant increased awareness of readmission risk.

\section{CONCLUSIONS}

Readmissions within 30 days of discharge after lung cancer resection are common and underestimated by metrics that focus only on the operating facility. Factors that increase the risk of readmission include preoperative comorbidities, procedure type, and socioeconomic factors. Although accurately predicting a future readmission in the preoperative setting is difficult, consideration of relevant risk factors should be a requisite component of discharge planning. Most important, patients who present with an early readmission are at high risk of subsequent death and demand maximum attention and care.

\section{References}

1. Jemal A, Thun MJ, Ries LA, Howe HL, Weir HK, Center MM, et al. Annual report to the nation on the status of cancer, 1975-2005, featuring trends in lung cancer, tobacco use, and tobacco control. J Natl Cancer Inst. 2008;100:1672-94.

2. Detterbeck FC, Boffa DJ, Tanoue LT. The new lung cancer staging system. Chest. 2009; 136:260-71.

3. Lum HD, Studenski SA, Degenholtz HB, Hardy SE. Early hospital readmission is a predictor of one-year mortality in community-dwelling older Medicare beneficiaries. J Gen Intern Med. 2012;27:1467-74.

4. Farjah F, Wood DE, Varghese TK, Massarweh NN, Symons RG, Flum DR. Health care utilization among surgically treated Medicare beneficiaries with lung cancer. Ann Thorac Surg. 2009;88:1749-56.

5. Readmissions reduction program [homepage on the Internet]. 2013. Available at: http://www.cms.gov/Medicare/Medicare-Fee-for-Service-Payment/AcuteInpatient PPS/Readmissions-Reduction-Program.html. Accessed November 20, 2013.

6. Lucas DJ, Haider A, Haut E, Dodson R, Wolfgang CL, Ahuja N, et al. Assessing readmission after general, vascular, and thoracic surgery using ACS-NSQIP. Ann Surg. 2013;258:430-9.

7. STS advocacy monthly [homepage on the Internet]. 2012. Available at: http:// www.sts.org/advocacy/beltway-briefings. Accessed November 20, 2013.

8. Boffa DJ, Allen MS, Grab JD, Gaissert HA, Harpole DH, Wright CD. Data from the society of thoracic surgeons general thoracic surgery database: The surgical 
management of primary lung tumors. J Thorac Cardiovasc Surg. 2008;135: 247-54.

9. Rueth NM, Parsons HM, Habermann EB, Groth SS, Virnig BA, Tuttle TM, et al. Surgical treatment of lung cancer: predicting postoperative morbidity in the elderly population. J Thorac Cardiovasc Surg. 2012;143:1314-23.

10. Warren JL, Klabunde CN, Schrag D, Bach PB, Riley GF. Overview of the SEERMedicare data: content, research applications, and generalizability to the united states elderly population. Med Care. 2002;40(8 Suppl). IV-3-18.

11. Greene F, Page D, Fleming I, Fritz A, Balch C, Haller D, et al, eds. AJCC Cancer Staging Handbook: From the AJCC Cancer Staging Manual. 6th ed. New York: Springer-Verlag; 2002.

12. Deyo RA, Cherkin DC, Ciol MA. Adapting a clinical comorbidity index for use with ICD-9-CM administrative databases. J Clin Epidemiol. 1992;45:613-9.

13. Klabunde CN, Potosky AL, Legler JM, Warren JL. Development of a comorbidity index using physician claims data. J Clin Epidemiol. 2000;53:1258-67.

14. SEER-Medicare: Calculation of comorbidity weights [homepage on the Internet]. 2010. Available at: http://healthservices.cancer.gov/seermedicare/ program/comorbidity.html. Accessed July 1, 2013.

15. Hu Y, McMurry TL, Wells KM, Isbell JM, Stukenborg GJ, Kozower BD. Postoperative mortality is an inadequate quality indicator for lung cancer resection. Ann Thorac Surg. 2014;97:973-9.

16. R: A language and environment for statistical computing [homepage on the Internet]. Vienna, Austria: R Foundation for Statistical Computing; 2013. Available at: http://www.R-project.org/. Accessed June 1, 2013.

17. Freeman RK, Dilts JR, Ascioti AJ, Dake M, Mahidhara RS. A comparison of length of stay, readmission rate, and facility reimbursement after lobectomy of the lung. Ann Thorac Surg. 2013;96:1740-6.

18. Varela G, Aranda JL, Jimenez MF, Novoa N. Emergency hospital readmission after major lung resection: prevalence and related variables. Eur J Cardiothorac Surg. 2004;26:494-7.
19. Handy JR Jr, Child AI, Grunkemeier GL, Fowler P, Asaph JW, Douville EC, et al Hospital readmission after pulmonary resection: prevalence, patterns, and predisposing characteristics. Ann Thorac Surg. 2001;72:1855-60.

20. Maniar HS, Bell JM, Moon MR, Meyers BF, Marsala J, Lawton JS, et al. Prospective evaluation of patients readmitted after cardiac surgery: analysis of outcomes and identification of risk factors. J Thorac Cardiovasc Surg. 2014; 147:1013-8

21. McDevitt J, Kelly M, Comber H, Kelleher T, Dwane F, Sharp L. A populationbased study of hospital length of stay and emergency readmission following surgery for non-small-cell lung cancer. Eur J Cardiothorac Surg. 2013;44: e253-9.

22. Costantino ME, Frey B, Hall B, Painter P. The influence of a postdischarge intervention on reducing hospital readmissions in a Medicare population. Popul Health Manag. 2013;16:310-6.

23. Fernando HC, Landreneau RJ, Mandrekar SJ, Hillman SL, Nichols FC, Meyers B, et al. Thirty- and ninety-day outcomes after sublobar resection with and without brachytherapy for non-small cell lung cancer: results from a multicenter phase III study. J Thorac Cardiovasc Surg. 2011;142:1143-51.

24. Kozower BD, Sheng S, O'Brien SM, Liptay MJ, Lau CL, Jones DR, et al. STS database risk models: predictors of mortality and major morbidity for lung cancer resection. Ann Thorac Surg. 2010;90:875-83.

25. Howlader N, Noone AM, Krapcho M, Garshell J, Neyman N, Altekruse SF, et al SEER Cancer Statistics Review, 1975-2010. Bethesda, MD: National Cancer Institute; 2013.

26. D'Agostino RS, Jacobson J, Clarkson M, Svensson LG, Williamson C, Shahian DM. Readmission after cardiac operations: prevalence, patterns, and predisposing factors. J Thorac Cardiovasc Surg. 1999;118:823-32.

27. Ferraris VA, Ferraris SP, Harmon RC, Evans BD. Risk factors for early hospital readmission after cardiac operations. J Thorac Cardiovasc Surg. 2001;122: 278-86.

\section{EDITORIAL COMMENTARY}

\section{The crisis of readmissions: Symptom or disease?}

Varun Puri, MD, MSCI

See related article on pages 2261-7.

Unexpected readmission after major lung resection is a relatively common occurrence and a major financial burden to the health care system. Although no clear data on lung cancer surgery are available, the Center for Medicare and Medicaid

\footnotetext{
From the Division of Cardiothoracic Surgery, Washington University School of Medicine, St Louis, Mo.

Supported by NIH grants K07CA178120 and K12CA167540-02 (Paul Calabresi Award).

Disclosures: Author has nothing to disclose with regard to commercial support. Received for publication Sept 25, 2014; accepted for publication Sept 25, 2014 Address for reprints: Varun Puri, MD, MSCI, Division of Cardiothoracic Surgery,

Washington University School of Medicine, Campus Box 8234, 660 S Euclid

Ave, St. Louis, MO 63110 (E-mail: puriv@wudosis.wustl.edu).

J Thorac Cardiovasc Surg 2014;148:2267-8

0022-5223/\$36.00

Copyright (C) 2014 by The American Association for Thoracic Surgery

http://dx.doi.org/10.1016/j.jtcvs.2014.09.088
}

Services estimates its annual costs for 30-day readmission to hospitals to be $\$ 26$ billion. ${ }^{1} \mathrm{As} \mathrm{Hu}$ and colleagues have shown in their article in this issue of the Journal, the overall long-term burden to society goes well beyond direct costs, because readmissions are associated with a significantly elevated risk of 90-day mortality. As part of the Affordable Care Act's Hospital Readmissions Reduction Program, public reporting of readmission rates has now been mandated, with potential financial penalties for institutions with excessive readmissions. Thus without a doubt preventing and appropriately managing readmissions in thoracic surgery is not only a medical necessity but a financial imperative for programs. This is especially true because competing nonoperative techniques for treating lung cancer are almost entirely free from the burden of readmissions.

$\mathrm{Hu}$ and colleagues, as well as previous authors, have treated readmission both as an important outcome variable in and of itself and as a predictor variable for further downstream events (death, disability, etc). For statistical 
TABLE E1. International Classification of Diseases, Ninth Revision diagnosis codes for relevant postoperative complications

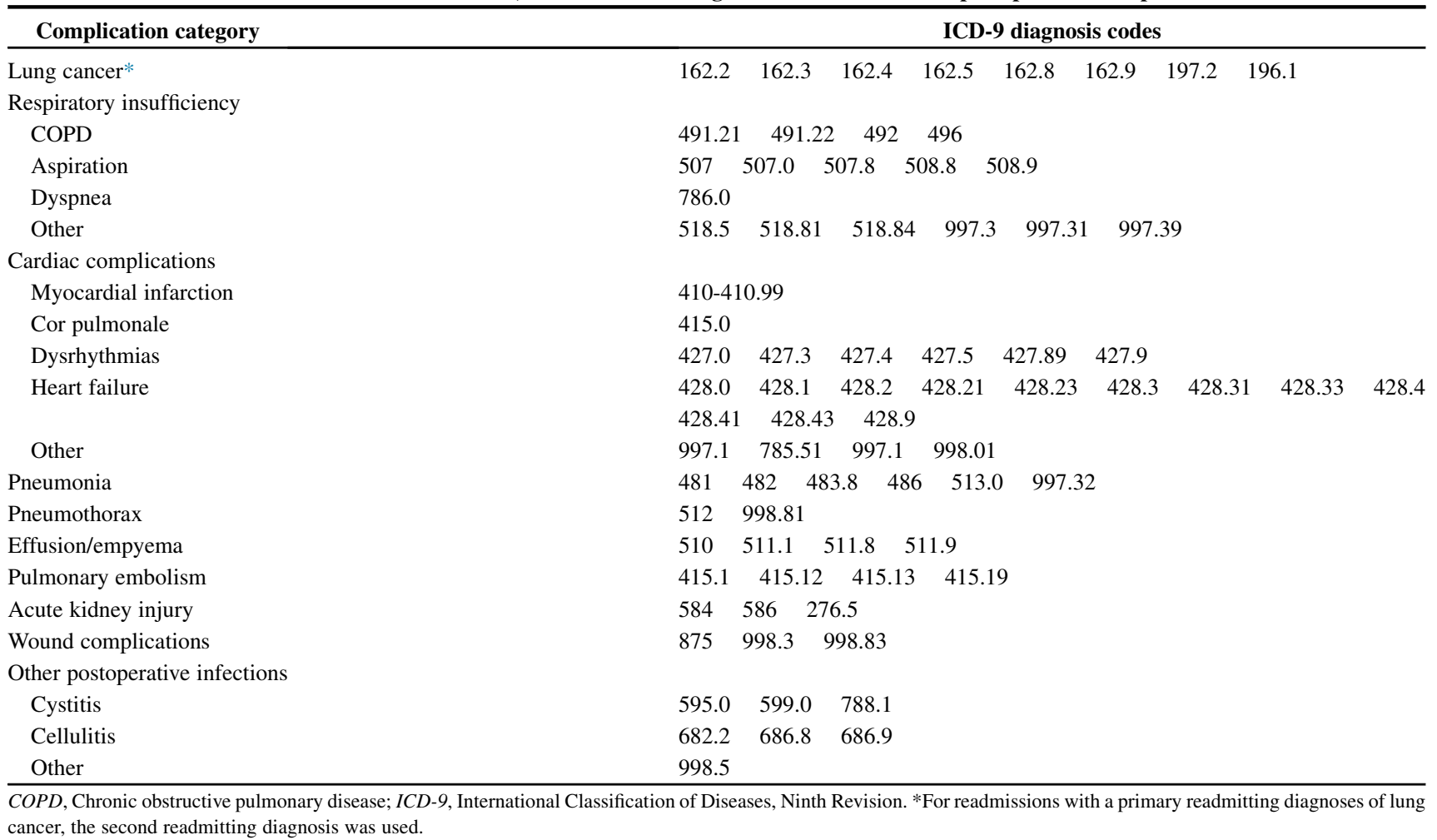

